\title{
A EVASÃO ESCOLAR: UMA METASSÍNTESE QUALITATIVA DE ESTUDOS BRASILEIROS (2015-2020)
}

Marcella Bordini ${ }^{1}$

Resumo: A evasão escolar tem sido temática de muitas pesquisas brasileiras. A fim de mapear os estudos brasileiros que tratam da evasão escolar como um todo em âmbito nacional e verificar suas causas e consequências para o ensino, busco me apoiar metodologicamente na Revisão Sistemática de Literatura (SARNIGHAUSEN, 2011), a qual procura percorrer as pesquisas de maneira crítica, por meio de uma metassíntese qualitativa. Foram selecionados 21 trabalhos, dentre artigos científicos, monografias e pesquisas publicadas em anais de congressos. Como respostas às perguntas desta pesquisa: a) Quais são as causas da evasão escolar?; b) Quais são as consequências da evasão escolar para o ensino?, os dados do mapeamento revelaram que o conceito de evasão é complexo, as causas são multifatoriais e as consequências podem representar uma catástrofe ao sistema de ensino.

Palavras-chave: Evasão escolar. Revisão sistemática da Literatura. Metassíntese qualitativa

\section{SCHOOL DROPOUT: A QUALITATIVE MATASYNTHESIS OF BRAZILIAN STUDIES} $(2015-2020)$

\begin{abstract}
The school dropout has been a frequent theme in many Brazilian researches. With the intention of mapping the Brazilian studies that are about school dropout in general in the national scenario and verify its causes and consequences to the learning, I myself search to support this research in its methodology in the Systematic Review of Litterature (SARNIGHAUSEN, 2011), that looks for treating the found litterature in a critical way, through a qualitative metasynthesis. There were selected 21 researches, among them there are scientific articles, monographies and researches that were published in congresses. As answers to this research's questions: a) What are the causes of school dropout? b) What are the consequences of school dropout to the learning?, the data of this mapping showed that the concept of dropout is complex, its causes are multifactorial and the consequences could represent a catastrophe to the learning system.
\end{abstract}

Key words: School dropout. Litterature systematic review. Qualitative metasynthesis

1 Doutoranda em Estudos da Linguagem pela Universidade Estadual de Londrina (UEL). E-mail: bordini.marcella@uel.br ou bordini.marcella@gmail.com 


\section{Introdução}

A evasão escolar é um fenômeno nacional e representa o abandono dos estudos, sem oficializar a entidade escolar onde o aluno está matriculado, acarretando prejuízos tanto para a escola que o acolheu, quanto para o estudante.

Este problema é causado por motivos internos e externos à instituição, que podem estar associados à falta de emprego, renda familiar, transporte, condições de saúde, dentre outros. Esta evasão pode ser definitiva, quando o aluno deixa de frequentar a escola, ou temporária, quando se ausenta por um período de tempo, retornando depois à unidade escolar. Embora o número de matrículas tenha aumentado nos últimos anos, o problema da evasão escolar ainda é expressivo.

Neste artigo, pretendo apresentar o mapeamento de estudos brasileiros que tratam da evasão escolar como um todo em âmbito nacional e verificar suas causas e consequências para o ensino. Para isso, busco me apoiar metodologicamente na Revisão Sistemática de Literatura (SARNIGHAUSEN, 2011), a qual procura percorrer as pesquisas de maneira crítica, por meio de uma metassíntese qualitativa.

Este presente trabalho está dividido em seções e subseções. São elas: a) metodologia da pesquisa; b) natureza da pesquisa; c) dados das pesquisas analisadas; d) análise dos dados da pesquisa; e) natureza dos trabalhos analisados; f) temas dos trabalhos analisados; g) conceito de evasão escolar; h) causas e consequências da evasão escolar; i) considerações finais da pesquisa.

\section{Metodologia da Pesquisa}

Foi selecionado o google acadêmico para a realização desta pesquisa, delimitando o período de publicação (2015-2020), com a inserção das seguintes palavras-chave, ambas entre aspas: "causas da evasão escolar", gerando 439 resultados, dos quais foram selecionados 19 trabalhos e as palavraschave "evasão escolar: causas e consequências", gerou 35 resultados, dos quais foram selecionados 2 trabalhos. Ao todo, foram lidos 21 trabalhos, dentre artigos científicos, monografias de cursos e pesquisas publicadas em anais de congressos.

Seguem as pesquisas selecionadas:

\begin{tabular}{|c|c|c|c|}
\hline Título do trabalho & $\begin{array}{l}\text { Natureza do } \\
\text { trabalho }\end{array}$ & $\begin{array}{l}\text { Ano de publi- } \\
\text { cação }\end{array}$ & Local de publicação \\
\hline $\begin{array}{c}\text { Evasão escolar: um estudo da evolução do aban- } \\
\text { dono escolar em uma escola da rede pública } \\
\text { estadual em Macapá-AP }\end{array}$ & Artigo científico & 2016 & RCE - Inhumas (GO) \\
\hline Evasão no ensino superior & Artigo científico & 2018 & Nativa - Revista de Ciências Sociais do Norte do MT \\
\hline $\begin{array}{l}\text { Álcool: uma das causas na evasão e abandono } \\
\text { escolar do adolescente }\end{array}$ & Artigo científico & 2018 & $\begin{array}{l}\text { Revista Valore, Volta Redonda, } 3 \text { (Edição Especial): 587-595., } \\
2018 \text { - RJ }\end{array}$ \\
\hline $\begin{array}{l}\text { A participação da família na escola: desdobra- } \\
\text { mentos sobre a evasão escolar e a educação } \\
\text { profissional e tecnológica na lógica neoliberal }\end{array}$ & Artigo científico & 2017 & EBR - Educação Básica Revista - UFSCAR - SP \\
\hline Evasão escolar: outros caminhos possíveis & $\begin{array}{l}\text { Publicação em } \\
\text { ANAIS }\end{array}$ & 2018 & $\begin{array}{l}\text { Anais III Congresso Internacional Uma Nova Pedagogia } \\
\text { para a Sociedade Futura | ISBN 978-85-68901-15-1 | p. | } \\
\text { set. } 2018 \text { - RS }\end{array}$ \\
\hline Evasão escolar: velhos problemas, novos olhares & $\begin{array}{l}\text { Publicação em } \\
\text { ANAIS }\end{array}$ & 2018 & $\begin{array}{l}\text { v. 8, n. 1, 2018: Anais do XIV Encontro de Iniciação Cientí- } \\
\text { fica da UNI7 - CE }\end{array}$ \\
\hline $\begin{array}{l}\text { Causas da evasão escolar na percepção dos Estu- } \\
\text { dantes evadidos: o caso do curso de Licenciatura }\end{array}$ & Artigo científico & 2020 & $\mathrm{RBIC}-\mathrm{SP}$ \\
\hline $\begin{array}{c}\text { Evasão de jovens do ensino médio: causas in- } \\
\text { traescolares segundo os evadidos de uma escola } \\
\text { pública }\end{array}$ & Artigo científico & 2016 & $\begin{array}{l}\text { Revista CAMINE: Caminhos da Educação, Franca, v. 8, n. } \\
\qquad 2,2016 . \\
\text { ISSN 2175-4217 - SP }\end{array}$ \\
\hline Causas da evasão escolar no ensino técnico & Artigo científico & 2018 & $\begin{array}{c}\text { Signos, Lajeado, ano 39, n. 2, p. 115-131, 2018. ISSN 1983- } \\
0378 \text { - RS }\end{array}$ \\
\hline
\end{tabular}




\begin{tabular}{|c|c|c|c|}
\hline $\begin{array}{c}\text { A evasão escolar na universidade aberta do brasil: } \\
\text { uma análise dos cursos ofertados no polo de } \\
\text { cruzeiro do sul - acre }\end{array}$ & TCC & 2015 & Cruzeiro do Sul- AC \\
\hline $\begin{array}{l}\text { Reflexões sobre a educação de jovens e adultos } \\
\text { no Brasil: as implicações da evasão escolar na vida } \\
\text { do estudante trabalhador }\end{array}$ & TCC & 2017 & $\mathrm{UFC}-\mathrm{CE}$ \\
\hline $\begin{array}{l}\text { Evasão escolar na educação superior: de que } \\
\text { indicador estamos falando? }\end{array}$ & Artigo científico & 2016 & $\begin{array}{l}\text { Est. Aval. Educ., São Paulo, v. 27, n. 66, p. 908-937, set./dez. } \\
\text { 2016- SP }\end{array}$ \\
\hline Evasão escolar: um problema, várias causas & Artigo científico & 2015 & $\begin{array}{c}\text { REBES - ISSN } 2358-2391 \text { - (Pombal - PB, Brasil), v. 5, n. 4, } \\
\text { p. } 30-35 \text {, out.-dez., } 2015\end{array}$ \\
\hline $\begin{array}{c}\text { Análise das Causas da Evasão na Educação a } \\
\text { Distância em uma Instituição Federal de Ensino } \\
\text { Superior }\end{array}$ & $\begin{array}{l}\text { Publicação em } \\
\text { ANAIS }\end{array}$ & 2015 & $\begin{array}{l}\text { Anais do XXVI Simpósio Brasileiro de Informática na Edu- } \\
\text { cação (SBIE 2015) } \\
- \text { AL }\end{array}$ \\
\hline $\begin{array}{l}\text { Fatores que podem interferir na evasão escolar } \\
\text { em uma instituição de ensino superior privada }\end{array}$ & Artigo científico & 2018 & $\begin{array}{l}\text { Revista Cesumar Ciências Humanas e Sociais Aplicadas, v. 23, } \\
\text { n. 2, p. 205-228, jul./dez. } 2018 \text { - ISSN 1516-2664 - PR }\end{array}$ \\
\hline $\begin{array}{l}\text { A educação a distância e suas tecnologias: um es- } \\
\text { tudo sobre a satisfação dos discentes e causas da } \\
\text { evasão escolar nos cursos de graduação da ufrn } \\
\text { na modalidade ead do polo currais novos/RN }\end{array}$ & $\begin{array}{l}\text { Publicação em } \\
\text { ANAIS }\end{array}$ & 2018 & $\begin{array}{l}\text { XV Congresso Brasileiro de Ensino Superior à distância - } \\
\text { RN }\end{array}$ \\
\hline $\begin{array}{l}\text { A evasão escolar como consequência da avaliação } \\
\text { da aprendizagem }\end{array}$ & TCC & 2019 & $\mathrm{AL}$ \\
\hline A evasão escolar & $\begin{array}{l}\text { Publicação em } \\
\text { ANAIS }\end{array}$ & 2017 & $\begin{array}{l}\text { I Simpósio Estadual da iniciativa educação, pobreza e desi- } \\
\text { gualdade social - TO }\end{array}$ \\
\hline $\begin{array}{l}\text { Educação profissional e evasão escolar em con- } \\
\text { texto: motivos e reflexões }\end{array}$ & Artigo científico & 2017 & Ensaio: aval. pol. públ. Educ., Rio de Janeiro. 2017 \\
\hline $\begin{array}{l}\text { Evasão e abandono escolar na } \\
\text { educação básica no Brasil: fatores, } \\
\text { causas e possíveis consequências }\end{array}$ & Artigo científico & 2017 & $\begin{array}{l}\text { Educação Por Escrito, Porto Alegre, v. 8, n. 1, p. 35-48, } \\
\text { jan.-jun. } 2017 \text { - RS }\end{array}$ \\
\hline $\begin{array}{l}\text { Evasão escolar e repetência de alunos na transi- } \\
\text { ção do ensino fundamental para o ensino médio } \\
\text { em escola do campo }\end{array}$ & TCC & 2019 & Universidade Federal da Fronteira Sul - Erechim - RS \\
\hline
\end{tabular}

\subsection{Natureza da Pesquisa}

Com base no objetivo principal deste trabalho -mapear estudos que tratam da evasão escola em âmbito nacional e verificar suas causas e consequências para o ensino - percorro aos estudos que abordam a Revisão Sistemática de Literatura como forma de produção e construção do conhecimento (SARNIGHAUSEN, 2011), estudos de metaanálise (LOVATTO et al., 2007) e a metassíntese como um dos procedimentos de análise da Revisão Sistemática (SARNIGHAUSEN, 2011).

Este estudo se caracteriza como pesquisa de cunho bibliográfico. Lima e Mioto (2007) ressaltam que este tipo é geralmente equiparado ao termo "revisão de literatura" ou "revisão bibliográfica", porém, é importante frisar que geralmente a revisão de literatura tem como objetivo contextualizar o trabalho empírico e, como tal, faz parte de toda pesquisa. Estudos bibliográficos pautados por análises de textos publicados, por outro lado, se baseiam em um conjunto ordenado de procedimentos de busca não-aleatória, tendo por objetivo a constituição de um amplo panorama do objeto estudado. São estudos que buscam aprofundar questões de modo a fornecer uma espécie de mapa para outros estudiosos do mesmo objeto.

Para as autoras, "reafirma-se a pesquisa bibliográfica como um procedimento metodológico importante na produção do conhecimento científico capaz de gerar, especialmente em temas pouco explorados, a postulação de hipóteses ou interpretações que servirão de ponto de partida para outras pesquisas" (LIMA; MIOTO, 2007, p. 44). Para as autoras, este tipo de pesquisa possibilita um amplo alcance de informações, bem como a utilização de dados dispersos em inúmeras publicações, possibilitando delinear o perfil de uma determinada área de estudo. Além disso, é preciso que o pesquisador esteja atento aos objetos propostos e aos pressupostos que 
envolvem o estudo, a fim de possibilitar a vigilância epistemológica, ou seja, permitir que ocorra a investigação do conhecimento presente no material escolhido para análise.

Para tanto, Lima e Mioto (2007) propõem uma sequência de procedimentos que devem ser cumpridos na realização de uma pesquisa bibliográfica:

Elaboração do projeto de pesquisa formulação da problemática de pesquisa;

Investigação das soluções: Coleta de dados, a qual envolve dois momentos distintos: levantamento da bibliografia e levantamento das informações contidas nesta;

Análise explicativa das soluções: Capacidade crítica do pesquisador para explicar ou justificar dados;

Síntese integradora (Metassíntese): Produto final do processo de investigação, resultante da análise e reflexão dos documentos.

O procedimento de coleta de dados referente à investigação das soluções acima descrita é denominado por Sarnighausen (2011) de Revisão Sistemática - método de busca de textos - a qual possibilita sintetizar informações relevantes, referentes a um assunto de interesse, pautadas em procedimentos específicos. Esta requer a identificação da literatura relevante para determinado assunto, devendo ser explícita, com objetivo, material e método bem definidos. O resultado deste trabalho deve ser uma obra de consulta que apresente vantagens aos seus usuários. Em suma, a Revisão Sistemática refere-se às estratégias de recuperação de textos em bases de dados e critérios de inclusão. Os procedimentos de análise pautados nesta metodologia podem ser de duas formas: meta-análise e metassíntese.

Lovatto et al. (2007) explicam que a metaanálise é uma das alternativas utilizadas para análise e sistematização das informações, configurando-se como um procedimento que combina resultados de vários estudos com a finalidade de criar uma síntese reproduzível e quantificável dos dados. Essa síntese contribui para a potência estatística na pesquisa dos efeitos dos tratamentos, incluindo aí precisão na estimativa e tamanho do efeito. Por meio da metaanálise, é possível obter uma visão geral da situação, em caso de resultados aparentemente discordantes. Meta-análises surgiram a partir de Smith e Glass (1977 apud LOVATTO, et al., 2007), que reuniram estatisticamente resultados de 375 pesquisas em psicoterapia, com a finalidade de provar que esta surtia efeitos, e dessa maneira, este método foi classificado de meta-análise. Diversas disciplinas passaram a fazer uso desse tipo de análise em ciências sociais, na educação, na medicina e posteriormente nas ciências agrárias.

Por meio da meta-análise, é possível obter novos resultados e evidenciar diferenças entre os tratamentos dos trabalhos tomados como base. Esta metodologia representa um meio muito interessante para justificar a necessidade de um experimento (FAGARD et al., 1996 apud LOVATTO; et al., 2007). A meta-análise permite fazer uma síntese dos dados contraditórios, independentemente do tamanho de sua potência analítica ou de sua amostra. Porém, o reagrupamento de vários experimentos corrobora uma maior precisão na avaliação do efeito do tratamento. Quanto maior a quantidade de informação, maior o aumento de comparações entre os temas, facilitando, dessa forma, o aumento da precisão analítica. Esta metodologia permite uma melhor representatividade dos dados, além de auxiliar na planificação e geração de uma nova hipótese.

Ainda no campo da meta-análise, Rodrigues (2002) afirma que existem dois tipos referentes a esta metodologia: a meta-análise quantitativa e a meta-análise qualitativa. A primeira objetiva a generalidade dos resultados encontrados, enquanto que a segunda tem por finalidade identificar, por 
meio de categorias, as semelhanças e controvérsias numa quantidade de estudos da mesma área de pesquisa; é um processo de descrição interpretativa, orientado por determinadas categorias teóricas.

No que se refere à metassíntese, há também duas formas de compreender o seu caráter de pesquisa: qualitativo ou quantitativo. Existe a denominação metassíntese qualitativa (SARNIGHAUSEN, 2011), a qual se configura como uma integração interpretativa das informações qualitativas, com o objetivo de realizar uma síntese do conjunto de dados e os resultados oriundos dessa metodologia não são analisados estatisticamente como numa pesquisa quantitativa.

Sarnighausen (2011, p. 98) ainda enfatiza que:

A estrutura da metassíntese é construída ao longo da análise de dados e, sendo assim difere dos demais trabalhos da literatura por ser único quando relacionado a determinado assunto. Parte da definição de um conjunto de referências, mas é moldado conforme a necessidade da pesquisa. Delinear o perfil de uma área, ou tema de pesquisa, é subjetivo e envolve a construção contínua de nuances que devem ser descartadas ou incorporadas à análise.

A metassíntese representa o tratamento dos resultados qualitativos de uma revisão sistemática, possibilitando a interpretação desses resultados, sejam de natureza qualitativa ou quantitativa, por meio da metassumarização e metarresumos. O primeiro reúne detalhes que caracterizam o texto científico em foco, enquanto que o segundo sintetiza e proporciona ampla compreensão conceitual dos resultados. A metassíntese é, em suma, a análise crítica das informações contidas nos textos.
Embora estudos de meta-análise e metassíntese sejam mais comuns nas áreas que publicam estudos empíricos de base quantitativa, nota-se que em pesquisas qualitativas este procedimento também pode ser útil (vide, por exemplo, trabalhos publicados em periódicos como Review of Educational Research).

Nesta pesquisa, adotei os parâmetros da metassíntese qualitativa, método que tem como objetivo recuperar as informações cruzadas de diversos textos, visando indicar fatos, fenômenos e perfis da área estudada. A metassíntese qualitativa é dividida em duas etapas:

a) Metarresumo - roteiro para leitura/leitura reflexiva: Descrição informativa dos estudos, identificação da obra no tempo e espaço, sua caracterização (tema central, objetivos, etc); é apresentado um quadro na seção de Apêndices desta Dissertação, contendo aspectos relativos às obras - a) natureza do trabalho (artigo de periódico, Dissertação de Mestrado, Tese de Doutorado), b) autor (es) do trabalho, c) título do trabalho, d) objetivos, e) metodologia, f) referencial teórico, g) resultados e h) tema - para facilitar ao pesquisador a análise dos dados das obras.

b) Metassíntese (Leitura interpretativa): Compreensão da obra no seu todo, relacionando aspectos dos textos com o objetivo da pesquisa bibliográfica. Nesta parte, incluo a associação de ideias, comparações, destaque para considerações relevantes e conclusivas, além da contribuição da obra para o estudo.

\section{Dados das pesquisas analisadas}

\begin{tabular}{|c|l|}
\hline \multicolumn{2}{|c|}{ PESQUISA 8 } \\
\hline Tema & Discussão das causas intraescolares da evasão \\
\hline Autor & Diniz e Quaresma (2016) \\
\hline Título do Trabalho & Evasão de jovens do ensino médio: causas intraescolares segundo os evadidos de uma escola pública \\
\hline Objetivos & Identificar os fatores que influenciam na decisão do aluno em evadir-se \\
\hline Metodologia & $\begin{array}{l}\text { Abordagem qualitativa descritiva, utilizando-se como instrumento de coleta de dados entrevistas semiestruturadas com } \\
\text { onze alunos evadidos }\end{array}$ \\
\hline
\end{tabular}




\begin{tabular}{|c|c|}
\hline Referencial Teórico & Klein (2008) - abandono e evasão - são conceitos distintos, porém, no trabalho, entendidos da mesma maneira. \\
\hline Resultados & $\begin{array}{l}\text { Apesar do ensino médio ser uma etapa muito importante na vida do jovem, percebe-se que a educação não tem sido sufi- } \\
\text { ciente para o desenvolvimento integral do educando, ou seja, para seu preparo para o exercício da cidadania e sua qualifica- } \\
\text { ção para o trabalho. } \\
\text { A reprovação, a baixa qualidade do ensino noturno, o bullying, a falta de interesse pelo ensino, a burocracia da escola, a } \\
\text { rotina e a dinâmica escolar constituem os principais motivos do abandono. Além disso, reconhecem que a convivência e o } \\
\text { relacionamento, principalmente com os pares, podem ser comparados como os melhores momentos vivenciados por eles } \\
\text { na escola, apesar de não serem estimulados e valorizados. }\end{array}$ \\
\hline \multicolumn{2}{|r|}{ PESQUISA 9} \\
\hline Tema & Causas da evasão escolar no ensino técnico \\
\hline Autor & Wentz; Zanelatto (2018) \\
\hline Título do Trabalho & Causas da evasão escolar no ensino técnico \\
\hline Objetivos & Identificar e analisar as principais causas que podem estar ligadas à evasão escolar do Ensino Técnico no Brasil \\
\hline Metodologia & Revisão integrativa e, através da leitura e avaliação de trabalhos acerca da temática da evasão escolar \\
\hline Referencial Teórico & $\begin{array}{l}\text { Christophe (2005), o termo "Educação Profissional" é amplo e abrange uma vasta gama de processos da educação, tais } \\
\text { como: Ensino Técnico, Ensino Profissionalizante, Formação Profissional, dentre outros; Sansil e Falcão (2014) - ensino } \\
\text { técnico no Brasil, de acordo com a LDB e Constituição Federal; FRITSCH; ROCHA; VITELLI (2015) - conceito de } \\
\text { evasão escolar, como sendo complexo; Vitelli e Fritsch (2016) - evasão escolar traz problemas para diversos setores. }\end{array}$ \\
\hline Resultados & $\begin{array}{l}\text { Causas da evasão - fatores relacionados aos estudantes: não identificação com o curso, incompatibilidade de horário com } \\
\text { o curso, fatores relacionados ao emprego/trabalho, preparação para o vestibular, estudos, dificuldade no acompanhamento } \\
\text { do conteúdo das aulas, atraso nas aulas, desmotivação em relação ao curso e dificuldades financeiras; } \\
\text { Fatores relacionados à escola: a formação do corpo docente, os recursos e estrutura das escolas bem como os processos e } \\
\text { as práticas escolares e pedagógicas. } \\
\text { Fatores relacionados ao sistema de ensino: os estudantes acabam desmotivando-se perante o curso e consequentemente } \\
\text { evadindo, por não possuírem as habilidades necessárias para a construção de conhecimentos essenciais, ou por não encon- } \\
\text { trarem sentido no aprender; podendo ser problemas oriundos de lacunas deixadas em níveis educacionais anteriores. } \\
\text { A grande maioria das evasões no Ensino Técnico avaliada neste trabalho está relacionada à dificuldade dos estudantes de } \\
\text { conciliar os estudos com a vida profissional. }\end{array}$ \\
\hline \multicolumn{2}{|r|}{ PESQUISA 10} \\
\hline Tema & Evasão escolar na universidade aberta do brasil - pólo cruzeiro do sul - Acre \\
\hline Autor & Fonseca (2015) \\
\hline Título do Trabalho & A evasão escolar na universidade aberta do brasil: uma análise dos cursos ofertados no polo de cruzeiro do sul - acre \\
\hline Objetivos & Identificar as principais causas para a evasão nos cursos de graduação oferecidos na modalidade à distância \\
\hline Metodologia & $\begin{array}{l}\text { O levantamento de percepções, através de entrevista realizada com os discentes, de forma a propiciar uma visão global } \\
\text { sobre os diferentes aspectos investigados; pesquisa exploratória e descritiva }\end{array}$ \\
\hline Referencial Teórico & $\begin{array}{l}\text { Mill (2012) - evasão escolar na UAB/EAD; Santos (2011) -evasão escolar como um dos problemas que preocupam as } \\
\text { instituições de ensino. }\end{array}$ \\
\hline Resultados & $\begin{array}{l}\text { principais fatores para a evasão escolar: falta de tempo, não conseguir conciliar o trabalho e os estudos, dificuldade para } \\
\text { organizar os estudos, pouco tempo para realizar as tarefas semanais. } \\
\text { Dentre as ferramentas que poderiam ser implementadas para reduzir a evasão escolar na educação superior à distância, } \\
\text { aponta-se a criação e disponibilização de bolsas de estudo, monitoria, PIBIC entre outras }\end{array}$ \\
\hline \multicolumn{2}{|r|}{ PESQUISA 11} \\
\hline Tema & Evasão escolar e EJA \\
\hline Autor & Farias (2017) \\
\hline Título do Trabalho & Reflexões sobre a educação de jovens e adultos no Brasil: as implicações da evasão escolar na vida do estudante trabalhador \\
\hline Objetivos & Analisar de que forma, e em que circunstâncias a evasão acontece nesta modalidade de ensino (EJA) \\
\hline Metodologia & Revisão bibliográfica \\
\hline Referencial Teórico & $\begin{array}{l}\text { Ceratti (2008) - muitas são as causas da evasão escolar; Santos (2003) - EJA como campo de oportunidade educacional } \\
\text { para os estudantes. }\end{array}$ \\
\hline Resultados & $\begin{array}{l}\text { O EJA é uma modalidade heterogênea e palco de muitos conflitos; o capitalismo deteriorou a sociedade; é preciso ir em } \\
\text { busca de uma sociedade mais igualitária. }\end{array}$ \\
\hline \multicolumn{2}{|r|}{ PESQUISA 12} \\
\hline Tema & Evasão escolar na educação superior \\
\hline Autor & Vitelli e Fritsch (2016) \\
\hline Título do Trabalho & Evasão escolar na educação superior: de que indicador estamos falando? \\
\hline Objetivos & $\begin{array}{l}\text { aborda o indicador educacional da evasão escolar na educação superior com o objetivo de distinguir e problematizar dife- } \\
\text { rentes concepções e usos do termo em produções acadêmicas. }\end{array}$ \\
\hline Metodologia & $\begin{array}{l}\text { revisão bibliográfica de escritos publicados entre } 1996 \text { e } 2015 \text { que abordam a evasão na educação superior e que apresen- } \\
\text { tam a fórmula de calculá-la. }\end{array}$ \\
\hline
\end{tabular}




\begin{tabular}{|c|c|}
\hline Referencial Teórico & Baggi e Lopes (2011) - reflexão mais sistemática sobre os vários significados do termo "evasão". \\
\hline Resultados & $\begin{array}{l}\text { Os resultados deste estudo evidenciam a fragilidade da eficácia de indicadores como ferramenta e/ou estratégia de ava- } \\
\text { liação da qualidade de cursos e instituições, problematizando a concepção e aplicação do indicador de evasão escolar na } \\
\text { educação superior. A falta de clareza na definiçã̃o e operacionalização compromete os resultados da mensuração e gera } \\
\text { equívocos na utilização comparativa. }\end{array}$ \\
\hline \multicolumn{2}{|r|}{ PESQUISA 13} \\
\hline Tema & Evasão escolar e suas causas \\
\hline Autor & Silva e Santos (2015) \\
\hline Título do Trabalho & Evasão escolar: um problema, várias causas \\
\hline Objetivos & $\begin{array}{l}\text { analisar os fatores que contribuem e desafiam educadores em sua práxis escolar, fazendo com que estes repensem seus } \\
\text { métodos. }\end{array}$ \\
\hline Metodologia & Revisão bibliográfica \\
\hline Referencial Teórico & Queiroz (2012) - evasão escolar está ligada a fatores intrínsecos e extrínsecos à escola. \\
\hline Resultados & $\begin{array}{l}\text { a evasão escolar continua sem resposta, mostrando-se como um problema que ainda está longe de ser resolvido e que irá } \\
\text { permanecer durante muito tempo. Diante dos atuais problemas vivenciados no contexto escolar, percebe-se que inúmeras } \\
\text { são as causas que têm colaborado com o alto índice da evasão escolar. Também se verifica que essas causas se distinguem } \\
\text { dois fatores: o fator interno e o externo. No entanto, a família é uma das principais causas do abandono escolar. A escola } \\
\text { também tem colaborado. Neste sentido, é preciso que a escola e a família fortaleçam cada vez mais os laços que as unem } \\
\text { no processo de aprendizagem. }\end{array}$ \\
\hline \multicolumn{2}{|r|}{ PESQUISA 14} \\
\hline Tema & Causas da evasão na EAD de uma instituição federal de ensino superior \\
\hline Autor & Reino, Hernández-Domínguez, Júnior, Carvalho, Barros, Braga (2015) \\
\hline Título do Trabalho & Análise das Causas da Evasão na Educação a Distância em uma Instituição Federal de Ensino Superior \\
\hline Objetivos & $\begin{array}{l}\text { analisar as principais causas da evasão de alunos de um curso de graduação a distância em uma Instituição Federal de En- } \\
\text { sino Superior brasileira. Os dados foram coletados a partir da aplicação de dois questionários: um direcionado aos alunos } \\
\text { evadidos e outro aos alunos remanescentes }\end{array}$ \\
\hline Metodologia & $\begin{array}{l}\text { métodos qualitativos e quantitativos para elencar e analisar os possíveis fatores que influenciaram a evasão dos alunos no } \\
\text { curso de bacharelado em Sistemas de Informação à distância da Universidade Federal de Alagoas, na modalidade de Edu- } \\
\text { cação a Distância }\end{array}$ \\
\hline Referencial Teórico & $\begin{array}{l}\text { Pinto e Mercado (2014) listam as principais preocupações da evasão escolar; Fávero e Franco (2006) - é necessário que o } \\
\text { educador mantenha contato com os educandos, tornando o ensino mais atrativo e de qualidade. }\end{array}$ \\
\hline Resultados & $\begin{array}{l}\text { Os resultados apontaram como principais fatores que motivaram a evasão, a falta de incentivo aos alunos pelo corpo do- } \\
\text { cente, as dificuldades de aprendizagem e o pouco tempo dedicado aos estudos. Outra contribuição relevante do estudo } \\
\text { foram as sugestões apresentadas pelos alunos remanescentes para a melhoria do curso tais como: o aumento do número de } \\
\text { aulas presenciais, a melhoria na comunicação do curso com os alunos e um maior apoio dos tutores online e presenciais }\end{array}$ \\
\hline \multicolumn{2}{|r|}{ PESQUISA 15} \\
\hline Tema & Fatores que podem interferir na evasão escolar em uma IES privada \\
\hline Autor & Silva, Moraes e Costa (2018) \\
\hline Título do Trabalho & Fatores que podem interferir na evasão escolar em uma instituição de ensino superior privada \\
\hline Objetivos & $\begin{array}{l}\text { Este estudo se destinou a fazer o levantamento de alguns dos fatores que podem levar os alunos do curso de Administra- } \\
\text { ção de uma instituiçãa de ensino superior privada do Estado do Amazonas a evadir. }\end{array}$ \\
\hline Metodologia & $\begin{array}{l}\text { Pesquisa de campo realizada por meio de aplicação de questionários aos alunos e entrevistas com professores e o coorde- } \\
\text { nador do curso, cujos dados foram tratados por meio das estratégias da estatística descritiva e da análise de conteúdo. }\end{array}$ \\
\hline Referencial Teórico & $\begin{array}{l}\text { A evasão escolar é um problema internacional que atinge a Educacão Brasileira e é caracterizado pelo abandono do aluno } \\
\text { às atividades escolares. [...., enquanto no setor público torna-se um investimento sem o devido retorno, nas instituicões } \\
\text { particulares é um dos principais motivos da perda de recursos, que poderiam ser empregados na melhoria da qualidade de } \\
\text { ensino [...] (STOFFEL; ZIZA, 2014, p. 1). } \\
\text { Santos Junior et al. (2014) relatam que ao partir do pressuposto de que um dos principais papéis das universidades e IES é } \\
\text { o de qualificar o corpo discente, preparando-os para o exercício profissional com a devida competência que deve ser obtida } \\
\text { durante o período no qual se encontram no sistema acadêmico e ainda levando em consideração que a prestação de contas } \\
\text { do uso de recursos públicos é medida usual em sociedades democráticas e o uso de receitas de instituições privadas impacta } \\
\text { diretamente em sua sustentabilidade financeira }\end{array}$ \\
\hline Resultados & $\begin{array}{l}\text { É possível afirmar que a evasão não pode ser solucionada com ações generalistas e focalizadas a apenas uma variável, visto } \\
\text { que este é um processo complexo e está relacionado a diversos fatores intervenientes, mesmo que seja aspecto preponde- } \\
\text { rante, considerando a alteração no perfil dos estudantes universitários nos últimos anos (RISTOFF, 2013). } \\
\text { Fatores não favoráveis à frequência ao curso, tais como os horários e os equipamentos e instalações, estes fatores não eram } \\
\text { os responsáveis pela evasão, na verdade os discentes estavam sujeitos a evasão por este não ser o curso desejado e pelo } \\
\text { mesmo não ter atendido às suas expectativas, ou seja, a origem da evasão nessa instituição é de natureza externa. }\end{array}$ \\
\hline
\end{tabular}

\section{PESQUISA 16}

\begin{tabular}{|l|l|}
\hline \multicolumn{2}{|c|}{ PESQUISA 16 } \\
\hline Tema & A EAD e suas tecnologias - caso de evasão escolar em curso de graduação \\
\hline Autor & Medeiros, Cruz e Silva (2018) \\
\hline
\end{tabular}




\begin{tabular}{|c|c|}
\hline Título do Trabalho & $\begin{array}{l}\text { A educação a distância e suas tecnologias: um estudo sobre a satisfação dos discentes e causas da evasão escolar nos cursos } \\
\text { de graduação da ufrn na modalidade ead do polo currais novos/RN }\end{array}$ \\
\hline Objetivos & $\begin{array}{l}\text { Identificar o grau de satisfação quanto ao uso das tecnologias e as causas da evasão dos acadêmicos dos cursos de gradua- } \\
\text { ção na modalidade a distância do Polo de Ensino à Distância de Currais Novos da UFRN }\end{array}$ \\
\hline Metodologia & $\begin{array}{l}\text { Análise longitudinal a qual, foi aplicado um questionário estruturado, para uma avaliação descritiva, com uma abordagem } \\
\text { quantitativa e qualitativa junto aos alunos do polo UFRN Currais Novos }\end{array}$ \\
\hline Referencial Teórico & $\begin{array}{l}\text { Um dos maiores problemas enfrentados pelo ambiente educacional é a evasão escolar, conceituada assim por Ávila (1992): } \\
\text { É o abandono da escola antes do término de um curso. Vários fatores contribuem para isso, avultando entre outros, o } \\
\text { pauperismo, como o mais ponderável. No ensino } \\
\text { de } 1^{\circ} \text { grau, a evasão escolar é mais acentuada a partir da } 3^{a} \text { série, pois que as crianças do meio econômico precário, tendo } \\
\text { atingido uma idade em que os pais as consideram capazes de os ajudar, passam a prestar pequenos serviços no lar ou fora } \\
\text { do lar, contribuindo muitas vezes financeiramente para o sustento da família (ÁVILA, 1992, p. 273). }\end{array}$ \\
\hline Resultados & $\begin{array}{l}\text { A análise das avaliaç̃oes feita pelos alunos dos cursos de graduação à distância, indicam um nível elevado de satisfação de } \\
\text { uma maneira geral e, particularmente, em relação ao ambiente tecnológico disponível (MOODLE e SIGAA). } \\
\text { De acordo com os resultados obtidos, pode-se verificar que a educação à distância é uma modalidade atrativa e possível. } \\
\text { Com um pouco mais de amadurecimento e trabalho focado à entender as necessidades dos discentes do EaD, a evasão será } \\
\text { uma barreira cada vez menos no futuro dessa modalidade de ensino. }\end{array}$ \\
\hline \multicolumn{2}{|r|}{ PESQUISA 17} \\
\hline Tema & Evasão escolar e avaliação da aprendizagem \\
\hline Autor & Silva (2019) \\
\hline Título do Trabalho & A evasão escolar como consequência da avaliação da aprendizagem \\
\hline Objetivos & $\begin{array}{l}\text { De acordo com os resultados obtidos, pode-se verificar que a educação à distância é uma modalidade atrativa e possível. } \\
\text { Com um pouco mais de amadurecimento e trabalho focado à entender as necessidades dos discentes do EaD, a evasão será } \\
\text { uma barreira cada vez menos no futuro dessa modalidade de ensino. }\end{array}$ \\
\hline Metodologia & Quali-quantitativa \\
\hline Referencial Teórico & $\begin{array}{l}\text { Bica (2017) faz a seguinte afirmação: } \\
\text { "A problemática da evasão e da repetência escolar no nosso país tem sido um dos grandes desafios afrontados pelas redes } \\
\text { do ensino público, pois os motivos e consequências estão unidos a fatores como social, cultural, político e econômico, bem } \\
\text { como a escola onde educadores tem colaborado a cada dia para o problema se agravar, frente a um método didático supe- } \\
\text { rado (p. 04). } \\
\text { O que vemos é que apenas as provas é quem ditam o desempenho escolar do aluno, sem levar em conta as especificidades } \\
\text { individuais de cada um, o que pode acarretar em punições ao invés de avaliações. Assim, os professores aproveitam muitas } \\
\text { vezes as provas como instrumentos ou ameaças, para chamar atenção dos alunos quando os mesmos não estão tão atentos } \\
\text { ao trabalho do professor, chegando até a fazer anúncios, como: "Estudem! Ou podem se dar mal na prova", conforme } \\
\text { aponta Luckesi, é nesse momento que a escola passa a ser vista como algo ruim, difícil por alguns alunos. }\end{array}$ \\
\hline Resultados & $\begin{array}{l}\text { De acordo com os resultados obtidos, pode-se verificar que a educação à distância é uma modalidade atrativa e possível. } \\
\text { Com um pouco mais de amadurecimento e trabalho focado à entender as necessidades dos discentes do EaD, a evasão será } \\
\text { uma barreira cada vez menos no futuro dessa modalidade de ensino. }\end{array}$ \\
\hline \multicolumn{2}{|r|}{ PESQUISA 18} \\
\hline Tema & Evasão escolar \\
\hline Autor & Linhares e Silva (2017) \\
\hline Título do Trabalho & A evasão escolar \\
\hline Objetivos & $\begin{array}{l}\text { A pesquisa sobre a evasão escolar no ensino médio caracteriza-se pela curiosidade de encontrar respostas verídicas para } \\
\text { responder a problemática traçada inicialmente, pois é a partir da pesquisa desenvolvida que se obteve fatos sobre o tema } \\
\text { em discussão que pudesse responder criticamente as causas da evasão escolar e suas consequências na vida social, pessoal e } \\
\text { profissional do indivíduo que abandona os estudos, cujo abandono muitas vezes causas danos irreparáveis na vida daquele } \\
\text { que evade da escola. }\end{array}$ \\
\hline Metodologia & $\begin{array}{l}\text { A análise dos dados coletados durante a pesquisa bibliográfica foram confrontados, comparando o pensamento dos auto- } \\
\text { res, tendo assim resultados verídicos e repassando para os leitores uma análise de forma minuciosa e crítica, visando desta- } \\
\text { car todos os detalhes abordados neste trabalho pesquisado }\end{array}$ \\
\hline Referencial Teórico & $\begin{array}{l}\text { Marconi e Lakatos (2013, p. 12) afirmam que: } \\
\text { A pesquisa bibliográfica é um apanhado geral sobre os principais trabalhos já realizados, revestidos de importância por se- } \\
\text { rem capazes de fornecer dados atuais e relevantes relacionados com o tema. O estudo da literatura pertinente pode ajudar } \\
\text { a planificação do trabalho, evitar duplicações e certos erros, e representa uma fonte indispensável de informações podendo } \\
\text { até orientar as indagações. }\end{array}$ \\
\hline Resultados & $\begin{array}{l}\text { Em vista ao grande aumento da evasão escolar no ensino médio, que também se alastra pelo ensino fundamental, o tema } \\
\text { em estudo tornou-se um grande desafio para a concretização desta pesquisa, tendo assim o intuito de apresentar informa- } \\
\text { ções relevantes e contribuir para uma reflexão crítica-atitudinal acerca da temática apresentada. }\end{array}$ \\
\hline \multicolumn{2}{|r|}{ PESQUISA 19} \\
\hline Tema & Educação profissional e evasão escolar \\
\hline Autor & Figueiredo e Salles (2017) \\
\hline Título do Trabalho & Educação profissional e evasão escolar em contexto: motivos e reflexões \\
\hline
\end{tabular}




\begin{tabular}{|c|c|}
\hline Objetivos & $\begin{array}{l}\text { analisar as causas de evasão no primeiro período de um curso técnico do Cefet/RJ, unidade Petrópolis. Buscou não apenas } \\
\text { identificar os fatores diretamente sinalizados pelos ex-alunos como causas do abandono, mas compreender as relações } \\
\text { entre os diversos elementos presentes em seus discursos }\end{array}$ \\
\hline Metodologia & $\begin{array}{l}\text { A investigação, que envolveu pesquisa documental e de campo, assumiu a forma de um estudo de caso. No que diz respeito } \\
\text { à abordagem, o estudo foi do tipo qualitativo e empregou a estratégia da análise de conteúdo para o tratamento do mate- } \\
\text { rial, coletado por intermédio de entrevistas semiabertas. }\end{array}$ \\
\hline Referencial Teórico & $\begin{array}{l}\text { Dore e Lüscher (2011, p. 775), } \\
\text { A evasão escolar tem sido associada a situações tão diversas quanto a retenção e repetência do aluno na escola, a saída do } \\
\text { aluno da instituição, a saída do aluno do sistema de ensino, a não conclusão de um determinado nível de ensino, o aban- } \\
\text { dono da escola e posterior retorno. Refere-se ainda àqueles indivíduos que nunca ingressaram em um determinado nível } \\
\text { de ensino, especialmente na educação compulsória, e ao estudante que concluiu um determinado nível de ensino, mas se } \\
\text { comporta como um dropout. }\end{array}$ \\
\hline Resultados & $\begin{array}{l}\text { Conforme demonstrado nessa pesquisa, a perda de alunos remete a aspectos que vão muito além daqueles considerados } \\
\text { por uma análise de cunho meramente economicista. Evasão diz sim respeito aos prejuízos financeiros advindos da impossi- } \\
\text { bilidade de manter os alunos em um determinado curso. Antes disso, porém, a temática insere-se no âmbito das discussões } \\
\text { que nos levam a questionar o tipo de formação que vem sendo oferecida pelas escolas, sobretudo aquelas voltadas à forma- } \\
\text { ção do jovem trabalhador. } \\
\text { Pensar o tipo de formação oferecida, bem como estar "sensivelmente atento" à trajetória dos estudantes que ingressam na } \\
\text { escola, tem a ver, é ressaltado, sobretudo com o papel do professor }\end{array}$ \\
\hline \multicolumn{2}{|r|}{ PESQUISA 20} \\
\hline Tema & Evasão e abandono escolar na EB \\
\hline Autor & Filho e Araújo (2017) \\
\hline Título do Trabalho & Evasão e abandono escolar na educação básica no Brasil: fatores, causas e possíveis consequências \\
\hline Objetivos & $\begin{array}{l}\text { Objetivou-se trazer para o debate algumas considerações sobre evasão e abandono escolar na educação brasileira. Veri- } \\
\text { fica-se a necessidade de ter como eixo a compreensão de suas dimensionalidades, pois suas formas de interpretação não } \\
\text { permitem chegar a uma definição precisa. }\end{array}$ \\
\hline Metodologia & Pesquisa bibliográfica \\
\hline Referencial Teórico & $\begin{array}{l}\text { Evasão, segundo Riffel e Malacarne (2010), é o ato de evadir-se, fugir, abandonar; sair, desistir; não permanecer em algum } \\
\text { lugar. Quando se trata de evasão escolar, entende-se a fuga ou abandono da escola em função da realização de outra ativi- } \\
\text { dade }\end{array}$ \\
\hline Resultados & $\begin{array}{l}\text { Fatores sociais, culturais, políticos e econômicos, bem como escolares, nos quais educadores têm colaborado a cada dia } \\
\text { para o problema se agravar, mediante a utilização de um método didático superado ou de uma prática cristalizada como } \\
\text { por inexperiência, acabam por desenvolver o conteúdo de forma descontextualizada e sem sentido para o aluno. } \\
\text { Criar formas de enfrentamento com a perspectiva do sistema, da escola e individual, capazes de amenizar as causas que } \\
\text { levam à superação de dificuldades para a diminuição da evasão e do abandono escolar, são discussões que poderão indicar } \\
\text { tal fenômeno. Por não terem sido ainda analisadas de forma adequada, necessitam de uma proposição alternativa para que } \\
\text { se possam reduzir os índices de evasão e abandono escolar em sentido amplo. }\end{array}$ \\
\hline \multicolumn{2}{|r|}{ PESQUISA 21} \\
\hline Tema & Evasão escolar na transição do ensino fundamental para o ensino médio \\
\hline Autor & Paliano (2019) \\
\hline Título do Trabalho & Evasão escolar e repetência de alunos na transição do ensino fundamental para o ensino médio em escola do campo \\
\hline Objetivos & $\begin{array}{l}\text { Investigar e analisar quais fatores podem vir a colaborar para a evasão e repetência na transição do ensino fundamental } \\
\text { para o ensino médio e nos três anos do ensino médio em uma escola do campo. } \\
\text { A presente pesquisa não tem como obrigatoriedade esgotar o tema mas, trazer reflexões e discussões a respeito de evasão } \\
\text { escolar, repetência de alunos no ensino fundamental e ensino médio }\end{array}$ \\
\hline Metodologia & Pesquisa de campo qualitativa e descritiva; questionários e dados da escola \\
\hline Referencial Teórico & $\begin{array}{l}\text { Também se faz necessário compreender os conceitos de abandono e evasão escolar. Conforme INEP- (1998), } \\
\text { [...] o conceito técnico de "Abandono" refere-se à situação em que o estudante deixa a escola num ano, mas retorna no } \\
\text { ano seguinte. Já a "Evasão" é situação em que o estudante sai da escola e não volta mais para o sistema. (INEP,1998 Apud } \\
\text { PARANÁ, 2018. p.10.). } \\
\text { Conforme Rubem Alves (1991), a missão do professor é formar cidadãos de bem, com conhecimentos de seus direitos } \\
\text { e deveres, para que o mesmo consiga viver em comunhão com o "jogo social", mas acima de tudo, os educadores estão } \\
\text { submissos às políticas da própria governamentais, e no caso das escolas do campo não é diferente }\end{array}$ \\
\hline Resultados & $\begin{array}{l}\text { Bem provável que a falta de comprometimento dos alunos no ensino fundamental tenha outras relações externas que } \\
\text { acabam refletindo no desempenho desses alunos, como uma possível falta de incentivo da família para que esses indivíduos } \\
\text { se dediquem mais nos estudos, e tendo em vista também que, na transição desses sujeitos do ensino fundamental para o } \\
\text { ensino médio, se encontrem numa fase biologicamente de instabilidade emocional elevada. } \\
\text { A falta de comprometimento com a educação, com as atividades escolares no ensino fundamental, conforme relatos dos } \\
\text { aluno }\end{array}$ \\
\hline
\end{tabular}




\section{Análise dos dados das pesquisas}

\subsection{Natureza das pesquisas analisadas}

Gráfico 1 - o próprio autor (2020)

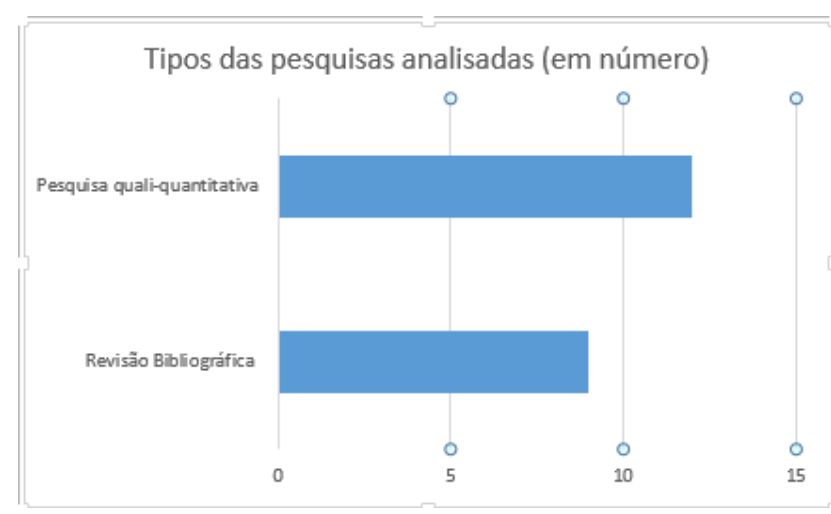

Um dado interessante presente no gráfico 1 é que a maior parte das pesquisas analisadas é de cunho quali-quantitativo, ou seja, optou-se por aplicação de questionários, entrevistas semiestruturadas, a fim de investigar mais de perto a situação da evasão escolar em nível nacional.

\subsection{Temas das pesquisas analisadas}

Gráfico 2 - o próprio autor (2020)

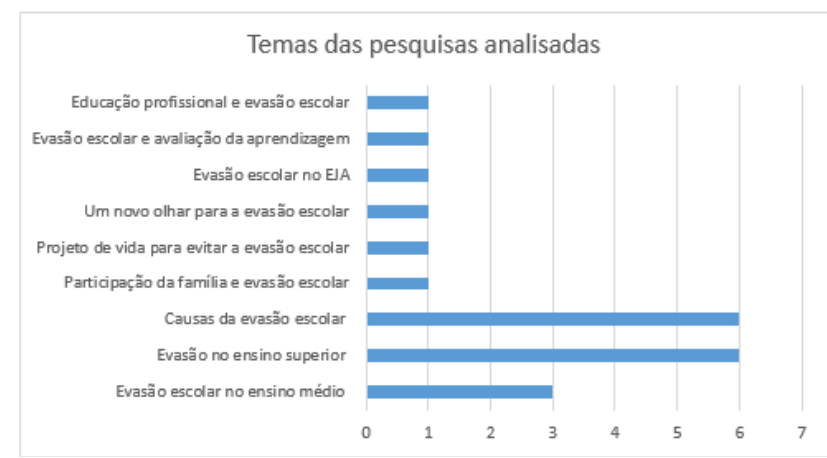

Com relação aos temas das pesquisas analisadas, observa-se que foram produzidos, na mesma proporção, trabalhos relativos às causas da evasão escolar, bem como a evasão escolar no ensino superior. Seria interessante que fossem produzidos mais trabalhos com relação à evasão escolar no ensino médio, bem como suas consequências para o ensino. Outro ponto importante é a participação da família relacionada à evasão escolar - mais trabalhos poderiam ser produzidos nesta área, a fim de verificar se a unidade familiar favorece ou impede esta evasão.

Diniz e Quaresma (2016) afirmam que apesar do ensino médio ser uma etapa muito importante na vida do jovem, percebe-se que a educação não tem sido suficiente para o desenvolvimento integral do educando, ou seja, para seu preparo para o exercício da cidadania e sua qualificação para o trabalho. A reprovação, a baixa qualidade do ensino noturno, o bullying, a falta de interesse pelo ensino, a burocracia da escola, a rotina e a dinâmica escolar constituem os principais motivos do abandono. Além disso, reconhecem que a convivência e o relacionamento, principalmente com os pares, podem ser comparados como os melhores momentos vivenciados por eles na escola, apesar de não serem estimulados e valorizados. Porém, em seu trabalho não correlaciona família à evasão escolar, atribuindo a fatores burocráticos institucionais a culpabilidade.

\subsection{Conceito de evasão escolar}

Com relação às pesquisas analisadas, o conceito de evasão é compreendido como um conceito complexo de ser explicado e analisado. Existe inclusive uma fórmula matemática para quantificar a evasão escolar de uma determinada unidade escolar. Existe uma diferença entre evasão e abandono - enquanto o primeiro representa a ausência de matrícula do aluno nos anos subsequentes, o segundo demonstra que o aluno se ausentou em um certo período do ano na escola, porém, retorna para a instituição escolar no ano seguinte. Segundo o INEP: [...] o conceito técnico de "Abandono" refere-se à situação em que o estudante deixa a escola num ano, mas retorna no ano seguinte. Já a "Evasão" é situação em que 
o estudante sai da escola e não volta mais para o sistema. (INEP,1998 Apud PARANÁ, 2018. p.10).

\subsection{Causas e consequências da evasão escolar}

Algumas causas da evasão - fatores relacionados aos estudantes: não identificação com o curso, incompatibilidade de horário com o curso, fatores relacionados ao emprego/trabalho, preparação para o vestibular, estudos, dificuldade no acompanhamento do conteúdo das aulas, atraso nas aulas, desmotivação em relação ao curso e dificuldades financeiras;

Fatores relacionados à escola: a formação do corpo docente, os recursos e estrutura das escolas bem como os processos e as práticas escolares e pedagógicas.

Fatores relacionados ao sistema de ensino: os estudantes acabam desmotivando-se perante o curso e consequentemente evadindo, por não possuírem as habilidades necessárias para a construção de conhecimentos essenciais, ou por não encontrarem sentido no aprender; podendo ser problemas oriundos de lacunas deixadas em níveis educacionais anteriores.

A grande maioria das evasões avaliadas nesta pesquisa está relacionada à dificuldade dos estudantes de conciliar os estudos com a vida profissional.

Com relação às consequências da evasão escolar, observou-se que fatores sociais, culturais, políticos e econômicos, bem como escolares, nos quais educadores têm colaborado a cada dia para o problema se agravar, mediante a utilização de um método didático superado ou de uma prática cristalizada como por inexperiência, acabam por desenvolver o conteúdo de forma descontextualizada e sem sentido para o aluno.

Criar formas de enfrentamento com a perspectiva do sistema, da escola e individual, capazes de amenizar as causas que levam à superação de dificuldades para a diminuição da evasão e do abandono escolar, são discussões que poderão indicar tal fenômeno.

\section{Considerações finais da pesquisa}

Com relação aos dados analisados nesta pesquisa, foi possível observar que o conceito de evasão escolar é muito complexo. É importante diferenciar o conceito de evasão e abandono escolar - o primeiro sugere que o aluno não tenha se matriculado mais em nenhuma instituição escolar, enquanto que o segundo sugere que o aluno tenha "perdido" um período do ano escolar, porém, ele retorna para a escola no próximo ano.

As pesquisas analisadas demonstraram que a maior parte delas é de cunho quali-quantitativa, o que é importante, uma vez que são pesquisas empíricas, utilizando-se de entrevistas semiestruturadas, questionários, dentre outros recursos.

As temáticas das pesquisas revelaram que a maioria se refere à evasão no ensino superior e as causas da evasão escolar. Outras pesquisas poderiam ser produzidas, como por exemplo, a evasão escolar no ensino médio, fatores mitigadores da evasão escolar, dentre outros.

Com relação às causas e consequências da evasão escolar - a primeira se refere aos motivos que levam os alunos a evadirem-se das instituições de ensino, que são fatores intraescolares ou extraescolares, ou seja, podem ou não estar diretamente relacionados ao ambiente escolar. As consequências da evasão escolar podem representar uma catástrofe ao sistema de ensino e à falta de profissionais qualificados, uma vez que os alunos evadem e não retornam aos estudos, para possível ascensão social.

Mais pesquisas poderiam ser feitas neste ramo para entendermos um pouco mais sobre o conceito de evasão, bem como suas causas e consequências para o ensino 


\section{REFERÊNCIAS}

ARAÚJO, A. S.; LUSTOSA, N. N. S.; CASTRO, N. N. Evasão escolar: um estudo da evolução do abandono escolar em uma escola da rede pública estadual em Macapá-AP. Revista científica de educação, Inhumas, v. 1, n. 1, p. 74-85, 2016.

BOTTON, E. A.; RODRIGUE, G. F.; SANTOS, N. C. G. R.; MARQUES, E. P. Evasão escolar: outros caminhos possíveis. In: III Congresso Internacional: Uma nova pedagogia para a sociedade futura, 2018, Rio Grande do Sul. Anais... Rio Grande do Sul: 2018. p. 363-367.

DINIZ, C. S.; QUARESMA, A. G. Evasão de jovens do ensino médio: causas intraescolares segundo os evadidos de uma escola pública. Revista Camine, Franca/SP, v.8, n.2, p.113-134, 2016

FARIAS, P. P. de. Reflexões sobre a educação de jovens e adultos no Brasil: as implicações da evasão escolar na vida do estudante trabalhador. 2017. 60f. Trabalho de Conclusão de Curso ao Curso de Pedagogia da Faculdade de Educação da Universidade Federal do Ceará, Fortaleza, Ceará. 2017.

FIGUEIREDO, N. G. S.; SALLES, D. M. R. Educação profissional e evasão escolar em contexto: motivos e reflexões. Ensaio: avaliação de políticas públicas educacionais, Rio de Janeiro, p. 1-37, 2017.

FILHO, R. B. S.; ARAÚJO, R. M. L. Evasão e abandono escolar na educação básica no Brasil: fatores, causas e possíveis consequências. Educação por escrito, Porto Alegre, v. 8, n.1, p. 35-48, 2017.

FONSECA, C. S. A evasão escolar na universidade aberta do brasil: uma análise dos cursos ofertados no polo de cruzeiro do sul Acre. 2015. 42f. Trabalho de Conclusão de Curso apresentado ao Curso de Administração Pública UNB/UAB, Cruzeiro do Sul, Acre. 2015.

FORTUNATO, M. R.; GONTIJO, S. B. F. Causas da evasão escolar na percepção dos Estudantes evadidos: o caso do curso de Licenciatura. Revista brasileira de iniciação científica, Itapetininga, v. 7, n.1, p. 55-76, 2020.

SOECKI, A. M.; SILVA, A. Z.; SANCHES, S.; SILVA, H. N.; ALMEIDA, A. P. F.; SOUZA, T. S. S.; AGNOLETTOO, E. Evasão no ensino superior. Nativa, v.7, n. 1, p.32-39, 2018.

LINHARES, A. C. F.; SILVA, A. C. S. A evasão escolar. In: Políticas educacionais, pobreza e desigualdade social: sujeitos e contextos sociais, 2017, Palmas. Anais...Palma, TO: UFT; EPDS; NEPED, 2017. p. 79-85.

MEDEIROS, E.; CRUZ, K. D. B.; SILVA, L. A. da. A educação a distância e suas tecnologias: um estudo sobre a satisfação dos discentes e causas da evasão escolar nos cursos de graduação da UFRN na modalidade EAD do polo currais novos/RN. In: XV Congresso Brasileiro de Ensino Superior a Distância/ IV Congresso Internacional de Educação Superior a Distância, 2018, Natal. Anais...Natal, RN: UniRede, 2018. p. 1-12

MOURA, F. C.; PRIOTTTO, E. M. T. P.; GUERIN, C. S. Álcool: uma das causas na evasão e abandono escolar do adolescente. Revista Valore, Volta Redonda, v. 3, p. 587-595, 2018.

PALIANO, F. Evasão escolar e repetência de alunos na transição do ensino fundamental para o ensino médio em escola do campo. 2019. 37f. Trabalho de Conclusão de Curso apresentado ao Curso Interdisciplinar em Educação do Campo: Ciências

REINO, L. R. A. C.; HERNÁNDEZDOMÍNGUEZ, A.; JÚNIOR, O. G. F.; CARVALHO, V. D. H.; BARROS, P. A. M.; BRAGA, M. M. Análise das Causas da Evasão na Educação a Distância em uma Instituição Federal de Ensino Superior. In: XXVI Simpósio Brasileiro de Informática na educação, 2015. Anais..., 2015. p.91-100.

SARNIGHAUSEN, V. C. R. Revisão sistemática e metassíntese: medições de gases de efeito estufa (GEE) emitidos pela pecuária bovina brasileira. 2011. 149f. Tese (Física do Ambiente Agrícola) 
- Escola Superior de Agricultura - "Luiz de Queiroz" - ESALQ, Piracicaba. 2011da Natureza - Licenciatura da Universidade Federal da Fronteira Sul, Erechim, Rio Grande do Sul. 2019.

SILVA, E M. N.; SANTOS, J. O. Evasão escolar: um problema, várias causas. Revista brasileira de educação e saúde, Pombal/PB, v. 5, n. 4, p. 30-35, 2015.

SILVA, F. G. A.; AMORA, J. T. M.; PEIXOTO, K. L. V.; BEZERRA, M. F. Evasão escolar: velhos problemas, novos olhares. In: XIV Encontro de Iniciação Científica da UNI7, n.1, 2018, Ceará. Anais...Ceará: 2018. p. 1-13.

SILVA, R. C.; MORAES, A. F. M.; COSTA, G. V. Fatores que podem interferir na evasão escolar em uma instituição de ensino superior privada. Revista CESUMAR, v.23, n.2, p. 205-228, 2018.

SILVA, R. R. A evasão escolar como consequência da avaliação da aprendizagem. 2019. 51f. Trabalho de conclusão de curso ao curso de Pedagogia da Universidade Federal de Alagoas Campus do Sertão, Sertão, Alagoas. 2019.

SILVEIRA, R. B.; BRITTES, L. R. A participação da família na escola: desdobramentos sobre a evasão escolar e a educação profissional e tecnológica na lógica neoliberal. Educação Básica Revista, v. 3, n. 1, p. 89-106, 2017.

VITELLI, R. F; FRITSCH, R. Evasão escolar na educação superior: de que indicador estamos falando? Est. Aval. Educ, SP, v. 27, n. 66, p.908937, 2016.

WENTZ, A. G.; ZANELATTO, E. M. Causas da evasão escolar no ensino técnico. Revista Signos, Lajeado, v. 39, n. 2, p. 115-131, 2018.

Submissão: junho de 2020.

Aceite: março de 2021. 